\title{
Dia Mundial da Alimentação: duas décadas no combate aos problemas alimentares mundiais
}

\author{
World Food Day: two decades of struggle \\ against the world's food problems
}

Ana Íris Mendes COELHO'

Maria Teresa Fialho de Sousa CAMPOS'

Maria Lúcia Mendes LOPES²

Juliana Farias de NOVAES ${ }^{3}$

R E S U M O

A celebração do Dia Mundial da Alimentação ocorre no dia 16 de outubro e, a cada ano, é escolhido um tema relacionado aos problemas alimentares mundiais, e são desenvolvidas ações para combatê-las. O objetivo desta comunicação é fazer uma retrospectiva descritiva dos temas que têm contribuído para colocar em evidência os problemas que necessitam de ações efetivas para serem erradicados e, ao mesmo tempo, alertar a população sobre a urgência de medidas preventivas que garantam a sobrevivência às gerações futuras.

Termos de indexação: alimentos, desnutrição, fome, nutrição, dia mundial da alimentação.

\section{A B S T R A C T}

World Food Day is celebrated on October 16, and every year a theme related to global food problems is chosen, and strategies to solve these problems are developed. The objective of this communication is to present a comprehensive review of those chosen themes, by decade, from its creation until the beginning of the 3rd millennium. Such themes have contributed to substantiating the problems whose eradication requires effective actions, as well as to warning the population about the urgent need for preventive measures that will ensure the survival of future generations.

Indexing terms: food, malnutrition, hunger, nutrition, world food day.

\footnotetext{
1 Departamento de Nutrição e Saúde, Universidade Federal de Viçosa. Av. PH Rolfs, s/n, Campus Universitário, 36571-000,

Viçosa, MG, Brasil. Correspondência para/Correspondence to: A.I.M.COELHO.E-mail: <aicoelho@ufv.br>.

2 Departamento de Nutrição Básica e Experimental, Universidade Federal do Rio de Janeiro. Rio de Janeiro, RJ, Brasil.

3 Nutricionista, Universidade Federal de Viçosa. Viçosa, MG, Brasil.
} 


\section{N T R O D U Ç Ã O}

A intenção da Organização das Nações Unidas para Agricultura e Alimentação (FAO), com a criação do Dia Mundial da Alimentação (DMA), foi atrair a atenção do público e das estruturas do poder para a natureza e para as dimensões dos problemas alimentares em todo o mundo, desenvolver um sentimento de solidariedade e arregimentar apoio, em âmbito mundial, ao combate à fome, à desnutrição, à pobreza e às suas causas básicas, conscientizando a população mundial dos problemas relacionados à segurança alimentar e nutricional ${ }^{1-5}$. Essa organização defende que a desnutrição e a sua principal causa, a pobreza, podem e devem ser eliminadas, mas, para isso, é indispensável uma ação coordenada e permanente que integre os esforços individuais e os despendidos em cada nação ${ }^{5}$.

O dia 16 de outubro foi escolhido por coincidir com a data de fundação da FAO, em 1945, em Quebec, Canadá. Participaram dessa decisão 147 países-membros que estiveram presentes em 25 de novembro de 1979, para a vigésima sessão da Conferência ${ }^{1,2,4}$. Desde a sua criação, as atividades de comemoração envolvem escritórios regionais, comitês nacionais e organizações não-governamentais (ONG) em diversos países. O comitê mundial de segurança alimentar sugere que, além das instituições governamentais, a sociedade civil e o setor privado se organizem num esforço coletivo de mobilização nacional para questões relacionadas à alimentação. Essas atividades são coordenadas, na maioria dos países, por um Comitê do Dia Mundial da Alimentação6.

Lembrado em mais de 150 países, esse dia tem a finalidade de debater a segurança alimentar, buscar soluções para o problema da fome no mundo e garantir alimentos de qualidade e em quantidade suficiente para todos os cidadãos ${ }^{7}$. Como os problemas alimentares mundiais são bastante complexos, a mobilização desses países não se resume apenas à exposição do quadro da fome, mas representa um desafio na busca de soluções efetivas. A exposição dos problemas, com vistas a torná-los significativos na vida cotidiana para que haja uma mobilização mundial em torno deles, depende de um intenso trabalho de comunicação². Aumentar a consciência, a compreensão e a ação continuada a curto, médio e longo prazo sobre os temas complexos relativos à segurança alimentar para todos é o que se procura alcançar com esse evento mundial ${ }^{4}$.

O objetivo desta pesquisa é fazer uma retrospectiva histórica dos temas abordados no DMA, buscando, assim, contribuir para o conhecimento acerca desse dia.

\section{TEMAS DO DIA MUNDIAL D A A LIMENTAÇÃ O}

Anualmente, um tema específico é escolhido entre os grandes problemas mundiais (Quadro 1), e a partir dele são centralizadas iniciativas para combater o fato em evidência ${ }^{8} \mathrm{em}$ diversos países, incluindo conferências, seminários,

Quadro 1. Discriminação anual dos temas do Dia Mundial da Alimentação desde a sua criação.

\begin{tabular}{ll}
\hline Ano & \\
\hline 1981 & Alimentação em primeiro lugar \\
1982 & Alimentação em primeiro lugar \\
1983 & Segurança alimentar \\
1984 & Mulheres na agricultura \\
1985 & Pobreza rural \\
1986 & Os pescadores e a comunidade pesqueira \\
1987 & Pequenos fazendeiros \\
1988 & Juventude rural \\
1989 & Alimentação e meio ambiente \\
1990 & Comida para o futuro \\
1991 & Árvores para a vida \\
1992 & Comida e nutrição \\
1993 & Colhendo a diversidade da natureza \\
1994 & A água como fonte de vida \\
1995 & Alimentação para todos \\
1996 & A luta contra a fome e a desnutrição \\
1997 & Investir em segurança alimentar \\
1998 & Mulheres que alimentam o mundo \\
1999 & Juventude contra a fome \\
2000 & Um milênio livre de fome \\
2001 & Lutar contra a fome para reduzir a pobreza \\
2002 & Água: fonte de segurança alimentar \\
\hline &
\end{tabular}


debates, cerimônias de premiação, atividades específicas em instituições de ensino e divulgação nos meios de comunicação.

\section{Década de 1980 (1981 - 1990)}

Nos dois primeiros anos, o tema foi "Alimentação em primeiro lugar", tendo em vista o empenho de dirigentes e da sociedade civil mundial em estabelecer a alimentação como prioridade para as nações. A partir daí, os temas foram mais direcionados aos meios de produção e ao homem do campo e, finalizando a década, foram focalizadas a proteção ao meio ambiente e a produção de alimentos para uma população mundial em expansão.

Alimentação em primeiro lugar (1981 - 1982): no primeiro DMA, foi lançado um apelo para que se celebre esse dia em todo o mundo, até que todos os dias sejam dias de alimentação para todos $^{2}$. A preservação do direito humano à alimentação não pode se limitar à ajuda na forma de distribuição de alimentos, nem a iniciativas ocasionais, embora seja evidente que haja essa necessidade em situações de perigo ${ }^{9,10}$. A esse direito corresponde o dever de uma ação contínua e programada, capaz de asseverar, em primeiro lugar, alimentação suficiente nos vários países do mundo. Para reverter o quadro de pobreza absoluta e de condições precárias de alimentação é indispensável a cooperação internacional para o desenvolvimento das iniciativas propostas, que se traduz num esforço combinado de governos (todo o sistema econômico e político), das organizações (intergovernamental, não-governamental), das associações de voluntários, das igrejas e de outras comunidades.

Em 1982, o diretor geral da FAO, Edouard Saouma, lembrou que essa organização busca, desde a sua fundação, enfatizar a posição prioritária da alimentação e da agricultura no processo de desenvolvimento nacional e internacional, acrescentando, ainda, que "[...] devemos assegurar aos produtores de alimentos o direito de receber remuneração adequada pelos pesados investimentos de capital e de trabalho que realizam e, acima de tudo, deve ser feito um esforço para garantir a todas as pessoas o direito humano básico a um suprimento adequado de comida de boa qualidade e a um preço que seja justo tanto para elas como para aqueles que trabalham o solo"2 (p.131).

Segurança alimentar (1983): a falta de segurança alimentar foi abordada como um problema decorrente de divisões entre classes sociais, países e regiões. A contribuição dos homens para esse fenômeno é reconhecida como resultado da injustiça socioeconômica, proveniente de sistemas ideológicos e políticos, e de declarações de guerras ou guerrilhas, embora as calamidas naturais também tenham parte nessa tragédia. Milhões de seres humanos continuam suportando a fome, e a situação tende a piorar na Ásia, África e América Latina. Esse quadro requer que o sistema econômico, em todo o mundo, seja remodelado, originando um sistema econômico internacional que dê prioridade ética ao desenvolvimento de todo país e de todo ser humano, com uma distribuição mais eqüitativa de recursos necessários à sobrevivência das pessoas, aliando a concessão de comida à implementação de fatores que contribuam para o autodesenvolvimento concreto de todas as nações ${ }^{11}$.

Mulheres na agricultura (1984): a contribuição das mulheres para a agricultura foi discutida, ressaltando a necessidade de reconhecer o trabalho que desenvolvem e de proporcionar a elas maiores direitos como cidadãs. Aceita-se que essa atividade, marcada pela diversidade por combinar funções domésticas com produtivas, desempenha importante papel para a produção rural e, apesar disso, tende a ser marginalizada e pouco valorizada ${ }^{12-14}$.

Em algumas culturas específicas, os empregadores consideram as tarefas como adequadas à mão-de-obra feminina, o que contribui para a ampliação da oportunidade de trabalho assalariado no campo. Em outras regiões, o seu trabalho na agricultura esteve associado à migração dos homens em busca de outras 
atividades remuneradas, delegando a elas o encargo da cultura de subsistência ${ }^{15}$.

Pobreza rural (1985): os fatores associados à pobreza no meio rural e a necessidade de maior atenção a esse setor foram expostos nesse dia, incluindo avaliação do custo de produção e remuneração adequada dos produtores. Os governos ditavam preços de alimentos à custa da renda do fazendeiro, ignorando os custos reais do plantio e da colheita e a necessidade de melhorias tecnológicas no meio rural. A proposta de combate à pobreza rural requer o compromisso das nações com esse fim $^{16}$.

Os pescadores e a comunidade pesqueira (1986): essa proposta meritória da FAO chamou atenção não só para a pesca, mas principalmente para os pescadores, que totalizavam cem milhões de pessoas. Esse segmento populacional enfrentou condições de vida difíceis, como a migração sazonal, que resultou na separação de famílias, períodos de ociosidade forçada, distância de grandes centros e falta de assistência médica. Outros problemas com os quais a comunidade pesqueira tem convivido são a falta de organização dos meios de financiamento para compra de barcos e de instalações adequadas; a falta de armazenamento do produto da pesca em boas condições de conservação; a incerteza a respeito do dia seguinte; e os perigos da vida de pescador. Essa população pesqueira, o tipo de trabalho executado e as condições de vida na pesca mereceram apoio de toda a sociedade ${ }^{17}$.

Pequenos fazendeiros (1987): os pequenos agricultores representavam uma proporção importante da população ativa, particularmente nos países pouco industrializados. Entretanto, precisavam superar dificuldades, pois o fruto do trabalho desenvolvido dependia das condições ambientais e, geralmente, não são organizadas reservas para subsistência, as quais permitiriam vencer os entraves existentes durante o período de uma colheita ruim. Apesar da produção abundante, há sérias dificuldades de transporte, comercialização e conservação. Como toda a família participava da exploração agrícola, ficavam prejudicados aspectos relativos a cuidados básicos com a saúde, com os meios de informação e com a educação, limitando a expressão das suas opiniões na vida social e na política ${ }^{18}$.

O DMA, ao colocar em evidência a vida dos pequenos fazendeiros, possibilitou que as autoridades civis e organizações internacionais tivessem maior conscientização sobre a responsabilidade de todos na organização da vida rural.

Juventude rural (1988): a intenção foi discutir o trabalho infantil no campo e as alternativas para viabilizar a permanência da criança com a família em melhores condições de vida, evitando a exploração do trabalho infantil, garantindo-lhe o direito à educação e à saúde, oferecendo, conseqüentemente, melhores perspectivas para o futuro do jovem que vive no ambiente rural ${ }^{19}$.

Alimentação e meio ambiente (1989): o uso irracional dos recursos naturais, os desmatamentos indiscriminados, a poluição da água e do ar e, ainda, a crescente contaminação dos alimentos são problemas que, segundo a Organização das Nações Unidas para a Agricultura e a Alimentação, ameaçam a própria existência do homem na Terra. A degradação da terra se estende, praticamente, a todas as regiões em todos os continentes. Somente a erosão causada pela água provoca a perda anual de cerca de 25 bilhões de toneladas de solo, e a desertificação afeta cerca de 3,5 bilhões de hectares nas zonas áridas e semi-áridas. Paralelamente, o crescimento industrial ultrapassou muito os limites ambientais, e o planeta recebeu resíduos tóxicos e gases que criam o efeito estufa e a chuva ácida 5 .

A crise ambiental representa uma ameaça à produção alimentar, e os estudos realizados pela FAO mostraram que, a cada ano, de cinco a sete milhões de hectares de terras de cultivo são perdidos, principalmente nos países em desenvolvimento. Os milhões de hectares de florestas destruídos anualmente fazem desaparecer centenas de espécies únicas de plantas e de animais. Nas florestas tropicais existem, pelo menos, 80 mil espécies de plantas comestíveis, sendo que nenhuma é cultivada. Diante desses dados, a perda dessa vasta diversidade biológica 
já se apresentava como um dos mais graves problemas ambientais ${ }^{20}$.

Tendo em vista a perspectiva de crescimento populacional até o ano 2000, a estimativa, naquela época, era de que a produção de alimentos aumentaria em cerca de $40 \%$, ou mais, para eliminar a fome. Mas, para que a humanidade possa se sustentar em um futuro previsível, há necessidade de adoção de sistemas de agricultura, silvicultura e de pesca que se harmonizem com o meio ambiente ${ }^{5}$.

O DMA enfocou a necessidade de afiançar o direito de todos os povos à quantidade suficiente de alimentos, conservando, ao mesmo tempo, as dádivas da terra para gerações futuras, de forma a reduzir a pobreza e eliminar a violência que dela deriva ${ }^{20}$.

\section{Década de 1990 (1991 - 2000)}

Marcada pela preocupação com o meio ambiente e com o futuro das nações, o desafio dessa década foi manter a busca de soluções efetivas para a fome e para a pobreza, partindo das questões relacionadas à dificuldade de acesso ao alimento para outras mais abrangentes, como segurança alimentar e nutricional, integrando variáveis sociais, econômicas e políticas, com destaque para os grandes centros urbanos. As atividades do DMA enfocaram que o problema da fome não residia simplesmente na falta de alimentos, já que a produção mundial era suficiente para alimentar os 5,3 bilhões de habitantes ${ }^{21}$.

No início dos anos 90, os temas escolhidos para a comemoração desse dia estavam relacionados à preservação do meio ambiente como forma de possibilitar a sobrevivência das gerações futuras, destacando-se os recursos naturais do planeta e a importância das árvores, da biodiversidade e da água. A partir de 95, houve maior direcionamento para questões que conduziram à criação da FAO, que sustenta que a produção de alimentos deve ser priorizada e igualmente distribuída no planeta. A segurança alimentar, a valorização do trabalho da mulher e a participação da juventude nos problemas mundiais relativos à fome e à desnutrição também foram destacadas no final da década.

Comida para o futuro (1990): as nações de todo o mundo devem estar voltadas para a preservação efetiva do meio ambiente, para que as populações nascidas nas próximas décadas tenham alimentos suficientes para a sobrevivência. A projeção era de que, em 2025 , a população mundial atingiria 8,5 bilhões de pessoas. 0 problema é mais complexo do que simplesmente despertar a consciência pública para a conservação do meio ambiente e para a questão alimentar mundial, pois envolve a transferência de ciência e tecnologia para benefício do mundo em desenvolvimento, principalmente para o pequeno produtor e para o campesino sem terra ${ }^{21}$. O êxodo rural vinha sendo agravado por problemas ambientais, o que favorecia a concentração de pessoas em ambiente insalubre em áreas urbanas do terceiro mundo. A recuperação das comunidades rurais como condição de unidades econômicas viáveis requer incentivos apropriados e assistência prática para fortalecer os sistemas tradicionais de produção de alimentos mediante a utilização de tecnologias ambientais racionais, culturalmente apropriadas e cada vez mais produtivas 5 .

No Brasil, uma mensagem especial divulgada pela FAO sustenta a tese de que, se não forem promovidas mais ações nacionais e internacionais com vistas à proteção de recursos naturais e ao desenvolvimento sustentável, continuará a aumentar, em todo o mundo, o número de pessoas oprimidas pela pobreza, pela fome e por problemas de má nutrição. Essa mensagem alertou para o fato de que há milhões de hectares sendo degradados e destruídos por erosões, incluindo as florestas tropicais, o que reforçou a importância de conciliar o crescimento da produção de alimentos com a conservação de recursos naturais ${ }^{21}$.

Árvores para a vida (1991): para que haja desenvolvimento sustentável no planeta, deveria 
ser priorizada, em cada país, a conservação de recursos naturais. A falta do combate às perdas anuais de milhões de toneladas de solo que são destruídos pelas erosões e de milhões de hectares que são totalmente degradados, incluindo áreas onde há florestas tropicais, pesca predatória e poluição, inviabiliza esse desenvolvimento ${ }^{21}$.

Despertar a consciência das nações sobre a importância da árvore para o ecossistema como forma de proteger essa herança do planeta e de manter a Terra habitável foi o intuito deste tema ${ }^{22}$.

Comida e nutrição (1992): o tema convocou a sociedade a colocar um fim na porção crescente da humanidade que sofre de fome e desnutrição, com maior empenho na promoção do bem-estar nutricional genuíno, no acesso a uma alimentação adequada em todos os países e no alcance de uma verdadeira solidariedade entre todas as pessoas, para que o direito fundamental de cada indivíduo às condições de vida que mantenham a dignidade humana seja preservado $^{23}$. A reflexão girou em torno de duas vertentes: de um lado, a existência de meios para pôr um fim na fome e na má nutrição; de outro, a presença desses males, de forma crescente.

Colhendo a diversidade da natureza (1993): a diversidade da natureza representa um recurso global do qual todos os países e regiões dependem, pois é fonte de comida, combustível, roupas e medicamentos. Embora a generosidade da natureza assegure uma verdadeira riqueza, cujas características podem ajudar a humanidade a satisfazer as suas necessidades vitais, e ocorra utilização crescente de métodos avançados para assegurar essa biodiversidade, a destruição de habitats e ecossistemas está resultando na extinção de recursos naturais de forma alarmante e, uma vez que haja perda do material genético de uma espécie, os valiosos atributos a ela conferidos não podem mais ser recuperados ${ }^{24}$.

Nesse sentido, o tema desse ano focalizou a associação entre biodiversidade e biotecnologia para o bem-estar da sociedade, e o papel das comunidades, principalmente rurais, na conservação da biodiversidade, de forma a garantir segurança alimentar, agricultura sustentável e desenvolvimento rural, ambiental e do comércio internacional24.

Durante as celebrações em Roma, foi feito um apelo para conservação dos preciosos recursos naturais, enfatizando que o uso mais eqüitativo e com responsabilidade ${ }^{25}$ é uma obrigação moral da geração presente e uma condição para a sobrevivência das próximas ${ }^{24}$. Esses recursos devem ser aproveitados de maneira mais justa, sem extinguir a diversidade biológica e as fontes genéticas. A dedicação da FAO à diversidade de formas de vida existentes no planeta, tanto vegetais como animais, mobilizou mais de 140 países em torno do DMA desse ano. De acordo com o pronunciamento dessa organização, a biodiversidade deve ser conservada independentemente dos interesses de instituições ou empresas que pretendam patentear espécies por elas descobertas na natureza ou obtidas por pesquisa para não impedir o acesso dos países pobres a esses recursos ${ }^{26}$.

A água como fonte de vida (1994): a poluição dos rios e lagos e a devastação de florestas e matas, que podem alterar o ciclo hídrico, são alguns dos motivos que levaram a FAO a dar maior ênfase à divulgação da maneira como a escassez de água pode interferir na produção de alimentos e na qualidade de vida, tanto em zonas rurais quanto urbanas. Esse recurso natural esgotável pode e deve ser poupado, pois água e vida são inseparáveis, uma vez que a primeira é imprescindível à segunda. Entretanto, existem alguns fatores gerados, muitas vezes, por atos impensados dos homens, que podem comprometer o abastecimento de água daqui a alguns anos. Apesar de alguns países já estarem sofrendo com a falta desse recurso, pretendeu-se mostrar que ainda há tempo de poupar as fontes naturais e de garantir o abastecimento, no futuro, de uma água de qualidade ${ }^{27}$.

Alimentação para todos (1995): a urgência do interesse renovado dos países em desenvolver uma ação conjunta em prol das pessoas que, por várias razões, não podem satisfazer às suas 
necessidades essenciais direcionou a escolha desse tema. Nesse ano, foi reforçada a distribuição adequada de recursos para programas conduzidos pela FAO como forma de auxiliar o alcance da dignidade humana, buscando superar as barreiras existentes ${ }^{28}$.

A retomada dos princípios que conduziram a criação da FAO - quais sejam, livrar a humanidade do fantasma da fome mediante promoção da atividade agrícola planejada e da cooperação efetiva entre todos os países, tendo em vista que uma das principais causas que dificulta o acesso aos alimentos é a pobreza a que está entregue grande parte da população mundial - marcou o qüinquagésimo aniversário dessa fundação ${ }^{28}$. Toda nação deve atuar com base no conceito de segurança alimentar para que toda pessoa tenha, a todo momento, acesso físico e econômico aos alimentos de que necessita. Esse conceito está fundamentado em três pressupostos: assegurar produção adequada de alimentos, conseguir máxima estabilidade dessa produção e permitir a todos o acesso aos alimentos disponíveis ${ }^{29}$. A comemoração permitiu avaliar os fracassos e sucessos das ações efetivadas, até este momento, na construção de um sistema mundial de segurança alimentar. Diversas estratégias para o futuro foram discutidas com base na experiência adquirida ao longo dos 50 anos $^{30}$. Para 1996, uma das metas da organização foi priorizar os programas de incentivo à agricultura nas diversas nações. Enfatizou-se a importância do desenvolvimento da agricultura, principalmente nos países mais pobres, para que os governos favoreçam áreas para produção imediata de alimentos e invistam em ações que ajudem no combate à fome, considerando que a expansão da agricultura gera mais comida, empregos e recursos financeiros para os países ${ }^{29}$.

A luta contra a fome e a desnutrição (1996): a temática colocou em discussão "como um planeta com produção de alimentos em quantidade suficiente para todos convive, ao mesmo tempo, com mais de 800 milhões de pessoas sem o direito a uma alimentação adequada" ${ }^{31}$, dos quais 64 milhões estão na América Latina ${ }^{32}$. Ao lado dessa realidade, coexistem países com excesso de alimentos, e pessoas com excesso de peso ${ }^{31}$.

A persistência da pobreza ameaça as bases da estabilidade social e, conseqüentemente, o processo de desenvolvimento econômico emergente. O sofrimento rural e a migração para os centros urbanos aumentam o desemprego, causando concentração de pobreza nas grandes cidades, o que implica, entre outros aspectos, perda de terras férteis e aumento da poluição, violência e criminalidade ${ }^{32}$.

O compromisso assumido na Conferência Mundial de Alimentação, realizada em 1974, foi a erradicação da fome e da desnutrição no prazo de uma década. Entretanto, transcorridos mais de 20 anos desde essa conferência, essa meta ainda não foi atingida ${ }^{33}$.

Diante do exposto, uma das estratégias adotadas foi convocar uma Conferência Mundial de Alimentação, realizada em Roma no período de 13 a 17 de novembro de 1996, para discutir a adoção de políticas e ações efetivas no combate à fome, buscando renovar o compromisso de dirigentes, instituições e setores da sociedade civil de todo o mundo com a erradicação dessa que é a maior mazela da humanidade. A cúpula da FAO havia fixado nessa reunião com dirigentes mundiais metas para combater a fome, com o objetivo de reduzir para 400 milhões o número de pessoas famintas até o ano de 201533,34.

Dessa forma, os delegados abriram mão de acabar com a fome e optaram por tentar reduzir o número de famintos, o que foi alvo de críticas do presidente de Cuba, Fidel Castro, que qualificou de vergonhosos os países que não lutassem para acabar com a fome ${ }^{35}$. Tendo em vista que ela traz perda de potencial humano, desassossego social e político, miséria e morte, a única alternativa para combater esse mal é reagir. Um duplo desafio deve ser enfrentado: o de produzir quantidade suficiente de alimentos e o de tornar certo que cada indivíduo tenha acesso 
a eles - e, por conseguinte, que obtenha segurança alimentar.

Os avanços tecnológicos ocorridos nos últimos anos não foram capazes de restringir as disparidades, constatadas em diversos países, entre os rendimentos obtidos em fazendas modernas e nas demais. Entretanto, é possível, ao colocar em prática os atuais conhecimentos, restringir tais disparidades sem necessitar, para isso, de novas descobertas científicas. Em muitos países em desenvolvimento, a cadeia de transferência de tecnologia foi interrompida de forma que os produtores não conseguem expressar suas necessidades para o meio científico, enquanto os investigadores não repassam a eles as novas descobertas. É preciso fixar esse direito o mais cedo possível e desenvolver os sistemas de extensão, evitando a duplicação de esforços e a perda de recursos em um trabalho conjunto além dos limites nacionais.

Outros aspectos foram considerados, como a necessidade de promover sistemas de cultivo integrados mediante um planejamento global de desenvolvimento sustentável, sendo uma das ferramentas a serem utilizadas, sabiamente, a biotecnologia. A agricultura deve ser intensificada sem colocar em risco o ambiente, e as medidas deverão ser acompanhadas de investimento significativo nesse setor e no bem-estar da população rural que, assim, permanecerá em áreas rurais ${ }^{31}$.

Investir em segurança alimentar (1997): um dos desafios da comunidade mundial é a viabilização da segurança alimentar, cujo significado é bastante abrangente ${ }^{36}$. No Brasil, segurança alimentar e nutricional significa garantir a todos condições de acesso a alimentos básicos, seguros e de qualidade, em quantidade suficiente, de modo permanente e sem comprometer o acesso a outras necessidades essenciais, com base em práticas alimentares saudáveis, contribuindo, assim, para uma existência digna em um contexto de desenvolvimento integral da pessoa humana ${ }^{37}$.

Para a Aliança Cooperativa Internacional $(\mathrm{ACl})$, o investimento na agricultura é a chave que permitirá aos produtores e às suas organizações, incluindo as cooperativas, atender às crescentes necessidades nutricionais da população, destacando-se as áreas de recursos humanos e financeiros, especialmente para as mulheres, que são responsáveis por grande parte da produção agrícola em países em desenvolvimento ${ }^{36}$. O DMA apontou que é essencial criar incentivos para promover investimentos em setores e atividades que resultarão na viabilização da segurança alimentar e nutricional sustentável, não precisando criar novas estruturas, mas construindo redes a partir daquilo que já existe ${ }^{38-41}$.

Com a proposta de combinar em um só processo os resultados dos relatórios das conferências internacionais relacionadas à alimentação e segurança nutricional, o Comitê Mundial de Segurança Alimentar da FAO convocou os governos a apresentarem, em 1998, o primeiro relatório de acompanhamento das atividades em relação ao Plano de Ação da Cúpula Mundial da Alimentação ${ }^{41}$, cuja análise permitiria aos paísesmembros melhor aplicação de recursos.

Mulheres que alimentam o mundo (1998): o objetivo foi chamar atenção para a importância do papel feminino na segurança alimentar tanto para o domicílio quanto para a nação, bem como estimular o debate sobre a importante relação entre as questões de gênero e a segurança alimentar e nutricional sustentável ${ }^{42-44}$. Essa homenagem ao significativo papel da mulher na agricultura, na pesca e nas florestas e sua expressiva contribuição para a segurança alimentar da família ${ }^{8}$ ajudam a entender mais profundamente a capacidade delas para nutrir, amar e educar.

No Dia Internacional da Mulher, 8 de março, a FAO anunciou o tema do DMA de 1998, que destacava o papel feminino na produção de alimentos. Tanto no meio rural quanto nas áreas urbanas, elas são as principais responsáveis pela alimentação das crianças e de outros membros da família. As estatísticas confirmam que elas produzem mais da metade dos alimentos no mundo, tendo expressiva participação na 
estocagem, na manipulação e no processamento de alimentos, fato que sinaliza a tendência da feminilização da agricultura nos países em desenvolvimento ${ }^{45}$.

O diretor geral da FAO reconhece a contribuição fundamental da mulher para a segurança alimentar, particularmente nas áreas rurais de países em desenvolvimento, e destaca a importância da concessão de direitos igualitários no trabalho ${ }^{46}$. É evidente que há necessidade de cada país investir no treinamento e na produtividade de mulheres e conceder a elas dignidade legal e social.

Juventude contra a fome (1999): os jovens representavam um quinto da população mundial e são a maioria da população brasileira, razão da importância de sua participação efetiva no esforço de propiciar alimentação para todos ${ }^{7,4}$. Numa tentativa de envolver a participação juvenil nos programas de erradicação da fome destacaram-se, nesse ano, as contribuições importantes e o potencial dos homens e mulheres jovens no alcance do objetivo da Cúpula Mundial de Alimentação, que é reduzir para a metade os mais de 800 milhões de pessoas cronicamente desnutridas no mundo, até 2015. Jovens na faixa etária entre 15 e 24 anos representam mais de um bilhão em todo o mundo; $85 \%$ vivem em países em desenvolvimento, estando $60 \%$ na Ásia. Com adequado treinamento, suporte e acesso a recursos e serviços, eles poderão contribuir para alcançar as metas de segurança alimentar. Parte desse segmento populacional, que reside em áreas urbanas e em países desenvolvidos, pode desempenhar papel decisivo no combate à fome, nas próximas décadas, ao pressionar os governos quanto à execução dos compromissos assumidos durante a Cúpula Mundial de Alimentação $0^{4,47}$. A juventude pode dedicar parte do seu tempo para empreender esforços locais, nacionais e globais, a fim de garantir o direito à alimentação para todos ${ }^{47}$, representando, ainda, um exercício de cidadania em cada país.

$\mathrm{O}$ acesso de pessoas jovens aos serviços essenciais por meio do envolvimento em programas para desenvolvimento rural sustentável serviria para reduzir as migrações para área urbana e, ao mesmo tempo, aumentar a produção e a disponibilidade de alimentos nas áreas onde essa estratégia se faz mais necessária e urgente ${ }^{47}$.

Um milênio livre de fome (2000): nesse ano, a Organização para a Agricultura e Alimentação divulgou o documento "Pobreza e Fome: Um Trágico Vínculo", que visa estimular a discussão desse tema, além de propor algumas alternativas de combate à fome. Esse documento foi destinado à comunidade universitária, mas pretendeu também envolver docentes, estudantes do ensino médio e entidades com funções sociais que atuam na minimização do problema no mundo. O parecer da FAO é preocupante, pois sinalizou que, se o ritmo não fosse alterado, a meta estabelecida em Roma, em 1996, de reduzir para 400 milhões o número de famintos, não seria atingida nem em 2030, quando o mundo atingiria mais de três bilhões de pessoas comprometidas pela falta de alimentos e pela desnutrição $0^{48,49}$.

Para livrar da fome o novo milênio, foi reforçada a necessidade de ações que eliminem o problema permanentemente, o que requer medidas como aumento da produtividade agrícola e da renda das comunidades rurais, melhor acesso ao alimento e participação dos países em desenvolvimento no comércio global, dentre outras direcionadas às causas subjacentes da fome crônica, que continua afetando milhões de pessoas.

Os números evidenciam que, durante a primeira metade da década de 90 , houve redução anual de oito milhões de pessoas famintas. No entanto, esse valor é menos da metade da taxa necessária para o alcance da meta da Cúpula Mundial de Alimentação, o que implica que, se essa tendência persistir em 2015, haverá ainda 700 milhões de pessoas passando fome ${ }^{50}$. Esse panorama mostra uma perspectiva que precisa ser revertida durante o novo milênio, e o desafio é tornar, urgentemente, a erradicação desse problema uma realidade; para isso, a taxa de redução anual de famintos tem que ser mais expressiva. A eliminação das causas deve ocorrer de forma sustentável e permanente ${ }^{51}$. 


\section{Início do terceiro milênio (2001 - 2004)}

Lutar contra a fome para reduzir a pobreza (2001): o combate à fome deveria ser o primeiro passo para a redução da pobreza, de acordo com a FAO, pois essa é causa de enfermidades e mortes, afeta a capacidade de trabalho das pessoas e prejudica o aprendizado das crianças, promovendo um círculo vicioso da falta de saúde, que se transmite entre as gerações ${ }^{52,53}$. Acima de tudo, é uma violação ao direito fundamental à alimentação ${ }^{53}$.

A escolha do tema deveu-se à complexa conexão entre fome e pobreza na busca de mecanismos mais diretos de erradicação do problema ${ }^{54}$, chamando atenção para o fato de que, embora os esforços tenham contribuído para a queda do número de famintos, a velocidade com que os resultados se concretizam tem se mostrado insuficiente. Os dados indicaram que seriam necessários 60 anos para reduzir pela metade o número de pessoas famintas no mundo. Para alcançar esse objetivo, a taxa de redução deveria ser de 20 milhões por ano, e a avaliação desse ano indicou que esse valor estava bem abaixo de oito milhões ${ }^{54,55}$. O sucesso de 32 países em desenvolvimento, inclusive a China, que reduziu para 116 milhões a quantidade de pessoas famintas, tem incentivado a continuidade das ações da FAO. Nas duas últimas décadas, os países em desenvolvimento apresentavam 29\% de pessoas desnutridas, valor que, em 2001, era de $18 \%$, embora a população do mundo tenha aumentado ${ }^{54}$

Para a FAO, a maioria das estratégias de redução da pobreza não está, infelizmente, especificamente direcionada à fome. Os governantes vêm admitindo que, se a economia do país cresce, os benefícios chegam até os famintos, mas essa política não tem se mostrado efetiva. A compreensão da interseção entre nutrição, desenvolvimento e política constitui a base teórica da necessidade de responsabilidades compartilhadas entre os diversos segmentos da sociedade no combate aos problemas alimentares mundiais ${ }^{53}$.

Conscientizar a população sobre a difícil situação em que se encontram as pessoas desnutridas e estimular a participação de todos na luta contra a fome é um passo vital para a segurança alimentar ${ }^{53,56}$.

Jacques Diouf, diretor geral da FAO, pronunciou que não se pode aceitar que a fome desaparecerá com a própria eliminação da pobreza ${ }^{53}$. A distribuição de recursos deixou as comunidades rurais sem infra-estrutura vital e sem serviços públicos nas áreas de comunicação, cuidados com saúde e educação ${ }^{57}$. As estratégias têm que alcançar as áreas rurais, pois 70\% dos pobres e famintos estão nessas regiões ${ }^{53}$. Apesar de a agricultura empregar grande parte da força de trabalho nos países em desenvolvimento, o investimento nesse setor é pequeno ${ }^{57}$.

A alimentação nutritiva e segura, em quantidade e qualidade suficientes para se ter uma vida saudável, e o acesso à água potável segura requerem ações públicas imediatas ${ }^{56}$. Se a comida produzida fosse dividida igualmente entre os habitantes, todas as pessoas teriam ingestão diária de $2760 \mathrm{Kcal}$, mais que o suficiente para obter saúde e vida produtiva ${ }^{53}$.

Água, fonte de segurança alimentar (2002): a água é um dos recursos mais preciosos que a Terra fornece à humanidade. O futuro da espécie humana e de muitas outras pode ficar comprometido, a não ser que haja melhoria significativa dos recursos hídricos terrestres ${ }^{58}$.

Durante muito tempo, acreditou-se que ela era um recurso infinito; no entanto, a oferta de água doce no planeta é finita ${ }^{59,60}$, e sua renovação depende de condições ambientais resultantes ou conseqüentes das próprias ações do homem ${ }^{61}$. Um estudo da FAO, em 93 países em desenvolvimento, indica que algumas nações já a estão utilizando em maior velocidade do que a sua renovação, razão pela qual, em 2030, um em cada cinco países em desenvolvimento estará sofrendo com a sua escassez ${ }^{62}$.

Os especialistas na área indicam que $97 \%$ da água no mundo é muito salgada para ser usada na agricultura e na indústria; a doce corresponde a menos de $3 \%$; sendo que $2 \%$, aproximada- 
mente, está congelada nas calotas polares e o restante, cerca de $1 \%$, parcela que está ameaçada, é para servir a humanidade ${ }^{59}$. A agricultura utiliza cerca de $70 \%$ de toda a água doce retirada da Terra e, para alimentar uma população crescente, cada vez mais ela será usada para irrigar a produção de alimentos ${ }^{62,63}$. O grande desafio global, durante os próximos anos, será produzir mais alimentos com menos recurso aqüífero, assim, o desenvolvimento e a adoção de tecnologias que aumentem a eficiência do seu aproveitamento são focos de atenção. A implementação de técnicas agrícolas que promovam métodos de irrigação mais efetivos, a preservação da umidade da terra e a utilização da biotecnologia na produção agrícola para uso de sementes melhores, bem como o apoio adequado aos fazendeiros na adoção de tais tecnologias, são soluções que se apresentam no momento ${ }^{62,64}$.

O Brasil é privilegiado, pois possui $12 \%$ da concentração mundial de água doce e o maior reservatório subterrâneo do planeta, que é o Sistema Aqüífero Guarani. Entretanto, a distribuição no país é desigual, visto que $70 \%$ de água doce está na Amazônia, onde vivem apenas 7\% da população, razão do problema de escassez em algumas áreas ${ }^{65,66}$.

Os processos acelerados de urbanização, de industrialização e da expansão da produção agrícola têm deteriorado a qualidade de vida e agredido o mais vital dos recursos: a água ${ }^{58}$. Para cada metro cúbico de água residual contaminada que se descarrega em aqüíferos, oito a dez metros cúbicos da pura se tornam impróprias ao consumo ${ }^{67}$. Em cem anos, metade das áreas úmidas que abasteciam o planeta com água doce foi perdida, e verifica-se, cada vez mais, aumento crescente do consumo pelo homem ${ }^{59}$. Estimativas mais recentes da Organização das Nações Unidas indicam que a crise da água já tem data marcada, 2025, ano em que haverá a globalização da deficiência que hoje ocorre de maneira localizada ${ }^{61}$. A projeção, se nada for feito, é drástica, já que dois terços da população mundial poderão sofrer com a sua escassez, e duas, em cada três pessoas, viverão em países que enfrentarão condições de vida difíceis ${ }^{59,67}$. Em menos de 25 anos, cerca de cinco bilhões de pessoas estarão morrendo em áreas onde será difícil ou impossível atender à demanda ${ }^{68}$.

A situação atual é alarmante, pois 1,5 milhão de pessoas no mundo não têm acesso à água limpa; 30 milhões de pessoas por ano morrem de epidemias e doenças contagiosas veiculadas pela água poluída; e, a cada oito segundos, morre uma criança por causa de doenças com ela relacionadas, como disenteria e cólera ${ }^{59}$. Nas próximas décadas, poderão acontecer novos conflitos internacionais motivados pela disputa por esse recurso ${ }^{69}$. O Canadá, por meio de contratos, fornecerá 80 bilhões de litros de água para China e Austrália, e nos países árabes, ela já está sendo trocada por petróleo, na proporção de dois litros de petróleo por um litro de água ${ }^{59}$. Em regiões como o Oriente Médio e a bacia do rio Nilo, na África, crescem as previsões de que a água irá substituir o petróleo e será a grande causadora de discórdia ${ }^{69}$. Existem previsões de que, se houver uma Terceira Guerra Mundial, será pela disputa desse recurso ${ }^{70}$.

A celebração mundial desse tema, em 2002, é bem oportuna, visto que esse precioso recurso não está sendo utilizado de modo sustentável. Em muitos países em vias de desenvolvimento, a alimentação disponível depende dos lençóis freáticos usados na irrigação. Portanto, se não for efetivada uma melhor gestão, algumas regiões mais densamente povoadas do globo poderão sofrer graves crises. A exaustão sem controle dos lençóis freáticos é uma ameaça à segurança alimentar em vários países, entre eles China, Índia, Paquistão e quase todos os países do Oriente Médio e da África do Norte. O futuro da segurança alimentar desses países dependerá da maneira como os responsáveis gerenciarão, hoje, os recursos aqüíferos subterrâneos ${ }^{71}$, incluindo avaliação da cobrança pelo uso, atividade que requer a participação de representantes da sociedade ${ }^{72}$. Entende-se que a educação 
ambiental tem importante papel na sociedade, uma vez que busca uma relação equilibrada com a natureza, mobilizando os diferentes segmentos sociais para construção de uma sociedade ambientalmente sustentável ${ }^{73}$.

Em março desse ano, no Dia Mundial da Água, também foi enfocada a sua necessidade para o desenvolvimento das sociedades humanas, alertando que, em muitas partes do mundo, as aspirações de desenvolvimento humano, social e econômico dependem dos recursos hídricos que, hoje em dia, diminuem de forma progressiva, enquanto a demanda aumenta ${ }^{67}$. Houve sinalização para que em 2003 fosse reforçada a sua importância, celebrando o Ano Internacional da Água Doce ${ }^{74}$.

Todas essas iniciativas podem contribuir para que a humanidade, cada vez mais, tenha consciência da necessidade de proteger os mananciais e de racionalizar seu uso, por meio de uma política pública eficiente e eficaz que modifique comportamentos individuais e coletivos $^{72}$.

Trabalhar unidos para uma aliança internacional contra a fome (2003): muitos países têm assumido um compromisso verbal de lutar contra a fome, mas poucas nações têm feito, em ações práticas, o suficiente e na escala requerida ${ }^{75}$. Em junho de 2002, na Cúpula Mundial da Alimentação, cinco anos depois daquela ocorrida em Roma, líderes mundiais de estados e governos ou seus representantes renovaram o compromisso, feito em 1996, de lutar contra a fome, e conclamaram os envolvidos para fortalecerem seus esforços e agirem como uma aliança internacional nesse sentido ${ }^{76,77}$. O número de pessoas cronicamente famintas tem diminuído apenas 2,5 milhões por ano, durante os últimos oito anos. Nessa taxa, a meta de reduzir pela metade o número de famintos e de desnutridos só será atingida cem anos mais tarde, em $2115^{76}$.

As nações necessitarão trabalhar intensamente para criar um ambiente político e implementar programas que permitam superar os problemas relativos à fome e à pobreza, por isso, a comunidade global resolveu trabalhar unida, constituindo uma aliança internacional ${ }^{75}$ que incitará grupos diferentes, no mundo inteiro, para alcançar o objetivo comum ${ }^{77}$. Nesses grupos incluem-se produtores de alimentos, consumidores, firmas privadas, cientistas, acadêmicos, indivíduos, grupos religiosos, organizações não-governamentais e, ainda, governos de países ricos e pobres ${ }^{75}$. Não há previsão de criação de mecanismos novos; essa aliança fortalecerá iniciativas existentes, ajudará a efetivar a cooperação entre os diversos grupos e promoverá ações em comum, facilitando a troca de informações por rede e relatórios sobre o progresso dos resultados ${ }^{77}$. Seus sócios podem oferecer ajuda nas esferas de competência, que incluem advocacia, treinamento técnico e conselho de política para monitorar o progresso das estratégias. No entanto, a responsabilidade principal é de cada nação, ou seja, cada país deveria fixar seus próprios objetivos amparados no poder legislativo, desenvolvendo estratégias para avançar na implementação de programas cujo alvo seja a população faminta ${ }^{75}$. Isso significa que o testamento político é um imperativo para alcançar a meta da Cúpula Mundial da Alimentação e, à medida que a aliança internacional contra a fome se forma, um número crescente de líderes em diversos países está colocando essa luta na vanguarda de prioridades nacionais ${ }^{77}$.

O Brasil, como outros países em desenvolvimento, está estabelecendo aliança nacional no combate a esse problema ao implementar como prioridade o Programa Fome Zero, que é uma proposta de política de segurança alimentar elaborada por mais de cem especialistas, acadêmicos e representantes da sociedade civil ${ }^{77,78}$. O Ministério Extraordinário de Segurança Alimentar e Combate à Fome (MESA) foi criado para coordenar esses esforços, interligando as ações que visam garantir a todos os brasileiros qualidade, quantidade e regularidade no acesso à alimentação, iniciativa que deve se tornar um exemplo mundial78.

A biodiversidade a serviço da segurança alimentar (2004): esse ano traz de volta a 
preocupação de garantir a conservação e o uso sustentável da biodiversidade no planeta, já enfatizada no início da década de 90.

A intenção é evidenciar a importância da biodiversidade para que a população tenha acesso, de forma sustentável, aos alimentos. A proposta do tema é a utilização de práticas de agricultura sustentáveis tanto para alimentar a população quanto para proteger os oceanos, as florestas e outros ecossistemas que abrigam a diversidade biológica ${ }^{79}$.

A proteção às comunidades e aos povos indígenas, e de seu amplo patrimônio cultural relativo à biodiversidade, é outra preocupação que deve ser reconhecida, uma vez que a exploração abusiva de suas terras põe em risco esse patrimônio ${ }^{80}$.

Enfocar a biodiversidade como um meio de servir à segurança alimentar suscita um desenvolvimento sustentável e solidário, no qual os países devem ter como princípio a cooperação internacional.

\section{Décadas de 1980 e 1990 na América Latina e no Brasil}

Os estudos desenvolvidos pela FAO demonstraram que a década de 80 não apresentou resultados satisfatórios, na América Latina, quanto à melhoria do estado nutricional da população, haja vista que, em 1985, havia uma estimativa de 55 milhões de desnutridos. A projeção divulgada durante a Conferência da FAO para a América Latina e Caribe, realizada em 1990 em Santiago do Chile, era de que a América Latina poderia chegar ao século XXI com 62 milhões de subnutridos ${ }^{81}$.

Cerca de $20 \%$ da população mundial, que representam um bilhão de pessoas, estão doentes e subalimentados, conforme dados da Organização Mundial da Saúde, sendo os países em desenvol-vimento os mais atingidos. Essa tragédia poderia ser evitada uma vez que os países desenvolvidos possuem recursos e tecnologias para erradicar essas enfermidades no mundo ${ }^{82}$. $\mathrm{Na}$ verdade, a instalação de doenças é favorecida, desde a infância, pela falta da adequada subsistência, o que, em muitos casos, tem continuidade ao longo da vida. Essa situação pode levar à morte, sem levar em conta as seqüelas que a subnutrição pode causar no cérebro das pessoas que conseguem sobreviver, resultando em lesões irreparáveis. A cada cinco crianças que morrem na América Latina, três são brasileiras ${ }^{83}$.

No Brasil, a Campanha Ação da Cidadania Contra a Fome e a Miséria e pela Vida, coordenada pelo sociólogo Herbert de Souza, o Betinho, recebeu apoio da população, e a estimativa é de que milhões de pessoas, voluntariamente, trabalharam para isso em todo o país. Entre as atividades que marcaram essa campanha, destaca-se a proposta do Natal sem Fome, que visava viabilizar alimentação a 32 milhões de brasileiros, nesse período, para famílias em estado de miséria, incluindo cestas com alimentos e brinquedos ${ }^{26}$. O impacto da divulgação do Mapa da Fome, que demonstrou o estado de indigência em que viviam esses milhões de brasileiros, foi considerado por Feliciello \& Garcia $^{84}$ como um dos fatores que mobilizaram a sociedade brasileira em torno da campanha pela necessidade de dar alguma contribuição para reverter esse quadro. Segundo esses autores, essa divulgação teve mais ressonância na população do que o convívio com a pobreza em situações rotineiras, como a presença de meninos de rua nos semáforos, o aumento da violência e o isolamento de famílias em condomínios fechados, dentre outras. Cabe lembrar que - Mapa da Fome no Brasil, que identifica as principais carências alimentares por região, foi pioneiramente criado por Josué de Castro; seu livro Geografia da Fome, com primeira edição em 1946, tornou-se um clássico com repercussão mundial, já traduzido em 25 idiomas, abordando esse fenômeno em suas diferentes manifestações, e assinalou o início de denúncias ao mundo acerca do flagelo da fome que continua a afligir a humanidade ${ }^{85}$.

No país, a década de 90 foi marcada por avanços na questão da segurança alimentar e, a 
partir da primeira Conferência Nacional de Segurança Alimentar, consolidou-se o entendimento de que a sua implementação exigia uma parceria efetiva entre governo e sociedade civil ${ }^{39}$. Outros avanços conquistados, também nessa década, são relativos à preocupação com a proteção do meio ambiente, com a escassez da água e com a segurança nutricional sustentável. Apesar desses avanços há, ainda, necessidade de medidas governamentais mais concretas, com a participação da sociedade para benefício desta e das futuras gerações. Os esforços para o desenvolvimento de programas específicos a cada país devem ser apoiados e complementados por outras nações, mediante o estabelecimento de políticas integradas que gerem um desenvolvimento sustentável para todos ${ }^{85}$.

A promoção do DMA nessas regiões constitui mais uma oportunidade de discutir, com outros países, a busca integrada da erradicação da fome no mundo. Os anos que sucedem a década de 90 e marcam o início do terceiro milênio são promissores, pois se vislumbra, com o tema de 2003, uma aliança internacional a favor de um direito básico: o de se alimentar e, com o tema de 2004, a cooperação internacional para a preservação da biodiversidade a serviço da segurança alimentar. Nesse contexto, incorporam-se ao conceito de segurança alimentar e nutricional o respeito à diversidade cultural e o fato de que as práticas alimentares saudáveis sejam social, econômica e ambientalmente sustentáveis ${ }^{86}$.

\section{COMENTÁRIOS FINAIS}

Com a promoção anual do DMA, a FAO tem induzido a sociedade a discutir os problemas da fome e da desnutrição no mundo e as formas de buscar um desenvolvimento sustentável no planeta e melhores condições de vida às gerações futuras. Os resultados alcançados indicam a necessidade de estratégias mais agressivas, pois a velocidade com que elas se concretizam tem se mostrado insuficiente. É preciso que haja um entendimento de que essas ações não devem se restringir ao dia 16 de outubro.
Ao reunir em um único documento informações sobre os 24 anos de celebração do DMA, percebe-se a relevância de cada tema e que as questões que originaram a sua criação permanecem atuais, desafiando as nações ainda em 2005, quando serão comemorados os 25 anos da existência desse dia.

\section{REFERÊ NCIAS}

1. Mancuso AMC. Dia mundial da alimentação: lutar contra a fome para reduzir a pobreza. Nutr Pauta. 2001; 10(51):10-5.

2. Organização das Nações Unidas para Agricultura e alimentação comemorou Dia Mundial da Alimentação. Rev Hig Alimentar. 1982; 1(3/4): 131-2.

3. Notícias breves. Rev Saúde do Mundo. 1981; (Set./Out.):39.

4. Juventude contra a fome: boletim da Campanha Dia Mundial da Alimentação. Ágora. 1999; 1(1).

5. Organização das Nações Unidas para Agricultura e alimentação prioriza debate sobre meio ambiente e alerta para necessidade de ampliação da produção de alimentos. Nutrinews.1989; 4(52):4-5.

6. Food and Agriculture Organization. Nota informativa: o Dia Mundial da Alimentação. Brasília, (DF); $1997 a$.

7. Lopes M. Daniela Mercury vai para a cozinha na luta contra a fome. Folha do Meio Ambiente [Internet]. 1999 [acesso 2001 nov 4]; 10(98). Disponível em: http://www.folhadomeioambiente. com.br/fma-98/alimento.htm

8. Dia Mundial da Alimentação é comemorado em todo o mundo. Nutrição em Pauta [Internet]. 1998 [acesso 2001 mar 21]. Disponível em: URL: http:// www. nutricaoempauta.com.br/novo/33/matcapa. $\mathrm{html}$

9. John Paul II. Message to the II World Food Day [homepage on the Internet]. Rome. 1982 [cited 2001 Nov 4]. Available from: URL: http:// www.vatican.va/holy_father/john_paul_ii/ messages/index.htm

10. John Paul II. Message to the first World Day of Feeding [homepage on the Internet]. Rome. 1981 [cited 2001 Nov 4]. Available from: URL: http:// www.vatican.va/holy_father/john_paul_ii/ messages/index.htm

11. John Paul II. Message to the third World Day of the Feeding [homepage on the Internet]. Rome. 
1983 [cited 2001 Nov 4]. Available from: URL: http:/ /www.vatican.va/holy_father/john_paul_ii/ messages/index.htm

12. Bruschini C. Mulher e trabalho: uma avaliação da década da mulher. São Paulo: Nobel; 1985.

13. Garcia TEM. Participação da mulher rural no processo decisório família [tese]. Viçosa, MG. Universidade Federal de Viçosa: Imprensa Universitária; 1981.

14. Penna V. A mulher trabalhadora. In: Carvalho NV. A condição feminina. São Paulo: Vértice; 1988. p. 103-23.

15. Lopes MF. Redefinição social do papel da mulher na economia doméstica: da família camponesa à família assalariada [tese]. Viçosa, MG. Universidade Federal de Viçosa, Imprensa Universitária; 1983.

16. Reagan R. Proclamation 5393: World Food Day [homepage on the Internet]. 1985. [cited 2002 Mar 21]. Available from: URL: http://www.reagan. utexas.edu/resourse/speeches/1985/101685c.htm

17. John Paul II. Message to the sixth World Day of the Feeding [homepage on the Internet]. Rome. 1986 [cited 2001 Nov 4]. Available from: URL: http:/ /www.vatican.va/holy_father/john_paul_ii/ messages/index.htm

18. John Paul II. Message to the seventh World Day of the Feeding [homepage on the Internet]. Rome. 1987 [cited 2001 Nov 4]. Available from: URL: http:/ /www.vatican.va/holy_father/john_paul_ii/ messages/index.htm

19. John Paul II. Message to the eighth World Day of the Feeding [homepage on the Internet]. Rome. 1988 [cited 2001 Nov 4]. Available from: URL: http:/ /www.vatican.va/holy_father/john_paul_ii/ messages/index.htm

20. Alimentos e meio ambiente: mensagem da FAO no Dia Mundial da Alimentação. Alimentação Industrial, 1989. 1(8):2.

21. Dia Mundial da Alimentação: a preocupação da FAO com a produção de alimentos nas próximas décadas. Nutrinews. 1990; 6(64):5.

22. John Paul II. Message to the eleventh World Day of the Feeding [homepage on the Internet]. Rome. 1991 [cited 2001 Nov 4]. Available from: URL: http:/ /www.vatican.va/holy_father/john_paul_ii/ messages/index.htm

23. John Paul II. Message to the 12th World Food Day [homepage on the Internet]. Rome. 1992 [cited 2001 Nov 4]. Available from: URL: http:// www.vatican.va/holy_father/john_paul_ii/ messages/index.htm

24. Getty VM. WFD 1993: Harvesting Nature's Diversity. PEN pages. College of Agricultural Sciences [homepage on the Internet]. 1997 [cited 1997 May 14]. Available from: URL: http://www. penpages.psu.edu/penpages_reference/12101/ 121011084.htm

25. Food and Agriculture Organization Of The United Nations. Annual Review 6: World Food Day [homepage on the Internet]. 1995 [cited 1998 Abr 7]. Available from: URL: http://www.fao.org/review/ VIEW6e.HTM

26. Natal sem fome. Nutrinews. 1993; 8(100):3

27. Dia Mundial da Alimentação: a água como fonte de vida. Nutrinews. 1994; 10(113):3.

28. John Paul II. Message to the 15th World Food Day [homepage on the Internet]. Rome. 1995 [cited 2001 Nov 4]. Available from: URL: http:// www.vatican.va/holy_father/john_paul_ii/ messages/index.htm

29. Dia Mundial da Alimentação: alimentos para todos. Nutrinews. 1995; 11(125):20.

30. Food and education for all. The George Washington University Connect [homepage on the Internet]. Washington (DC), [updated 1995; cited 2002 Jul 3]. Available from: URL: http:// www.gwu.edu/ connect/ fooded3.html

31. Food and Agriculture Organization of the United Nations. Statement by the director-general on the occasion of World Food Day [homepage on the Internet]. Rome. 1996b [cited 1998 Mar 7]. Available from: URL: http://www.fao.org/dg/ wfdaye.htm

32. Food And Agriculture Organization of the United Nations. Embedded poverty threatens growth and stability in Latin America. [homepage on the Internet]. Rome. 1996a [cited 1998 Abr 7]. Available from: URL: http://www.fao.org/focus/e/ WFDay/WFEMb-e.htm

33. A fome preocupa o mundo. Nutrinews. 1996; 12(135):3.

34. Food and Agriculture Organization of the United Nations. Report of the World Food Summit; 1996 Nov 13-17. Rome: FAO; 1997. p.123.

35. Baptista F. Roma decreta fome para 400 milhões. Jornal da Cidadania [serial on the Internet]. 1996 [acesso 1996 jun 12]. Disponível: URL: http:// www.alternex.com.br/jcidadania/fome51.html

36. Comitê Codex Alimentarius do Brasil. Dia Mundial da Alimentação [homepage on the Internet]. Brasil. 1997 [acesso 1998 mar 20]. Disponível: URL: http:// www.orb.org.br/aciinf3.htm

37. Valente FLS. Do combate à fome à segurança alimentar e nutricional: o direito à alimentação adequada. Rev Nutr. 1997; 10(1):20-36.

38. Food and Agriculture Organization of the United Nations. World Food Day 1997 marks anniversary 
of founding with focus on "Investing in Food Security" [homepage on the Internet] [updated 1997; cited 1988 Apr 7]. Available from: URL: http://www.fao.org/food/wfd-e.htm

39. Serviço Social do Comércio. Dia Mundial da Alimentação. Informe Mesa São Paulo. São Paulo; 1997; p.3.

40. Serviço Social do Comércio. Dia Mundial da Alimentação [Internet] [atualizado 1997; acesso 1998 nov 12]. Disponível: URL: http:// www.rhol.com.br/alimen.htm

41. Forum Global de Segurança Alimentar e Nutricional Sustentável. Boletim do Fórum Global de Segurança Alimentar e Nutricional Sustentável. Brasília: Ágora; [periódico na Internet]. 1997. [acesso 1999 fev 5]; 1(2). Disponível: URL: http:// www.brnet.com.br/pages/rededma/plp/bolfgl2. html

42. Boletim da Rede Dma-Plp-Brasil. DMA-98. Mulher que alimenta o mundo [Internet]. Brasil. [atualizado 1998; cited1999 jan 7]. Disponível em: URL: http://www.brnet.com.br/pages/ rededma.plp

43. Forum Global de Segurança Alimentar e Nutricional Sustentável. Boletim do Fórum Global de Segurança Alimentar e Nutricional Sustentável [Internet]. 45-1998. [acesso 1999 fev 5]. Disponível em: URL: http://www.brnet.com.br/pages/rededma/ plp/bolfgl2.html

44. Food and Agriculture Organization of the United Nations announces theme for World Food Day 1998: women feed the world. Press Release 98/16 [homepage on the Internet]. Rome. 1998 [updated 1998; cited 2001 Jun 25]. Available from URL: http://www.fao.org.WAICENT/OIS/PRESS_NE/ PRESSENG/1998/pren9816.htm

45. Food and Agriculture Organization of the United Nations. Women feed the world: announces theme for World Food Day [homepage on the Internet]. Rome. 1998 [updated 1998; cited 1998 Nov 12]. Available from: URL: http://www.fao.org/dg/wfd

46. Food and Agriculture Organization of the United Nations. Statement by the director-general on the occasion of World Food Day [homepage on the Internet]. Rome. 1998b [cited 1998 Nov 12]. Available from: URL: http://www.fao.org/dg/ wfday98-e.htm

47. Food and Agriculture Organization of the United Nations announces theme for World Food Day/ Telefood 1999: youth against hunger. Press Release 99/25 [homepage on the Internet]. Rome. 1999 [cited 2001 Jun 25]. Available from: URL: http://www.fao.org./WAICENT/OIS/PRESS_NE/ PRESSENG/1999/pren9925.htm
48. Fome: uma triste realidade para um sexto da população da Terra. Nutrinews [serial on the internet]. São Paulo; 2000 [acesso 2001 nov 4]. Disponível: URL: http://www.nutrinews.com.br/ edições/Fome.html

49. Fuller RW. Campanha contra a fome no mundo [online]. CRIA; 1997.

50. Food and Agriculture Organization of the United Nations announces theme for World Food Day 2000: a millennium free from hunger. The agency calls for urgent action to eliminate underlying causes of hunger. Press Release 00/41 [homepage on the Internet]. Rome. 2000a [cited 2002 Jul 17]. Available from: URL: http://www.fao.org./ WAICENT/OIS/PRESS_NE/PRESSENG/2000/ pren0041.htm

51. Food and Agriculture Organization of the United Nations. World Food Day 2000 [homepage on the Internet]. Rome. 2000b [cited 2001 Dez 19]. Available from: URL: http://www.fao.org/wfd/ wfd2000-e.htm

52. Conselho Federal de Nutricionistas. Combater a fome para reduzir a pobreza: essa é a hora de apontar o verdadeiro inimigo [Internet]. Brasil. [atualizado 2001; acesso 2001 nov 6]. Disponível em: URL: http://www.cfn.org.br/variavel/noticia5. htm

53. Food and Agriculture Organization of the United Nations. Fight hunger to reduce poverty [homepage on the Internet]. Rome. 2001b [cited 2001 Out 30]. Available from: URL: http://www. fao.org/wfd/index.asp

54. More than 150 countries observe world food day under the theme fight hunger to reduce poverty. Press Release 01/70 [homepage on the Internet]. Rome. [updated 2001; cited 2002 Jul 17]. Available from: URL: http://www.fao.org./WAICENT/OIS/ PRESS_NE/PRESSENG/2001/pren0170.htm

55. Food and Agriculture Organization of the United Nations announces theme for World Food Day: fight hunger to reduce poverty. Press Release 01/52 [homepage on the Internet]. Rome. [updated 2001; cited 2002 Jul 17]. Available from: URL: http://www.fao.org./WAICENT/OIS/PRESS_NE/ PRESSENG/2001/pren0152.htm

56. Dia Mundial da Alimentação: combater a fome para reduzir a pobreza. Revista Qualidade em Alimentação-Nutrição [Internet]. 2001. [acesso 2002 mar 21]. Disponível em: URL: http://www. pontocritico.com.br/ nutricao/naintegra.htm

57. Fight hunger to reduce poverty. Telefood. Rome, 2001 [homepage on the Internet]. New York: First day cover design and text 1986 [updated 1986 Nov 14; cited 2002 mar 21]. Available from: URL: http://www.unicover.com/EA1BAOBF.HTM 
58. Água: um bem tão precioso [Internet]. Brasil. 2002b [acesso 2002 jul 17]. Disponível em: URL: http://www.geocities.com/ esabio/agua/agua.htm

59. Cia Nacional das Águas. Situação real e as perspectivas para o futuro da humanidade [Internet]. Brasília; 2002 [acesso 2002 jul 17]. Disponível em: URL: http://www.cianacioonal dasaguas.com.br/ artigo01.htm

60. Langone C. 22 de março: Dia mundial da água. Associação Brasileira de Entidades Estaduais de Meio Ambiente [Internet]. Brasil. 2002 [acesso 2002 out 11]. Disponível em: URL: http://www. agirazul.com.br/_livres/00000017.htm

61. Disperdício de água [Internet]. Brasil. 2002 [acesso 2002 jul 17]. Disponível em: URL: http://www. proplad. ufba.br/aguapurap2.htm

62. Food and Agriculture Organization of United Nations. Water: source of food security [homepage on the Internet]. Rome. 2002 [cited 2002 Out 10]. Available from: URL: http://www.fao.org/wfd/ index_en.asp

63. World Food Day: Food and Agriculture Organization calls attention to the vital role of water in agriculture [homepage on the Internet]. Rome. 2002a [cited 2002 Out 10]. Available from: URL: http://www.fao.org/english/newsroom/news/ 2002/ 9700_en.html

64. World Water Day 2002: agriculture needs to produce more with less water [homepage on the Internet]. Rome. 2002b [cited 2002 Out 10]. Available from: URL: http://www.fao.org/ WAICENT/OIS/PRESS_NE/english /2002/3340_ en.html

65. Miúra J. Água para todos. Folha do Meio Ambiente [Internet]. 2001 [acesso 2002 out 11]; 11(113). Disponível em: URL: http://www.folhadomeio ambiente.com.br/fma_113/agua/113.htm

66. Rodriguez FA. A grave questão da água no Brasil. Folha do Meio Ambiente [Internet]. 2000 [acesso 2002 out 10] 11(102). Disponível em: URL: http://www.folhadomeioambiente.com.br/ fma_102/onu102.htm

67. DMA: a celebração mundial da água. Águaonline [Internet]. 2002 [acesso 2002 jul 17]. Disponível em: URL: http://www.aguaonline.com.br/projeto2/ materia. asp?codigo $=196 \&$ sec $=$ ambiente \&atual

68. Associação Brasileira de Águas Subterrâneas [Internet]. Falta de água ameaça 2,7 bilhões de pessoas até 2025. Brasil. 2002 [acesso 2002 jul 17]. Disponível em: URL: http://www.abas.org/ clipping/ anteriores/0021.htm>.

69. Água: abundância e escassez [Internet]. Brasil. 2002a [acesso 2002 jul 17]. Disponível em: URL: http://www.comciencia.br/reportagens/agias/ aguas02.htm

70. A água nossa de cada dia preservai hoje [Internet]. Brasil. 2002 [acesso 2002 jul 17]. Disponível em: URL: http://www.agrobyte.com.br/agua.htm

71. Exaustão do lençol freático: ameaça oculta à segurança alimentar? Águaonline [Internet]. Brasil. 2002 [acesso 2002 jul 17]. Disponível em: URL: http://www.aguaonline.com.br/projeto2/ materia.asp? codigo $=347 \& \mathrm{sec}=$ ponto $\&$ atual

72. Planeta água ou mundo sedento? Águaonline [Internet]. Brasil, 2002 [acesso 2002 jul 17]. Disponível em: URL: http://www.aguaonline. com.br/projeto $2 /$ materia.asp? codigo $=203 \&$ $\mathrm{sec}=$ ponto\&atual

73. Educação ambiental é solução para problemas do meio ambiente? Águaonline [Internet]. Brasil. 2002 [acesso 17 jul 2002]. Disponível em: URL: http:// www.aguaonline.com.br/projeto2/materia.asp? codigo $=371 \&$ sesc $=$ ponto $\&$ atual

74. ONU apela por uso seguro e sustentável da água. Águaonline [Internet]. Brasil. 2002 [acesso 2002 jul 17]. Disponível em: URL: http://www. aguaonline.com.br/projeto2/materia.asp?codigo= $189 \&$ sec=agua\&atual

75. World Food Day/TeleFood 2003. International alliance against hunger [homepage on the Internet]. Rome. 2003 [cited 2003 Set 15]. Available from: URL: http://www.fao.org/wfd/infonote_2003 _en.htm

76. Working together for an international alliance against hunger [homepage on the Internet]. Rome. 2003 [cited 2003 Set 15]. Available from: URL: http://www.fao.org/wfd/index_en.asp

77. International Alliance Against Hunger, theme of World Food Day/TeleFood 2003 [homepage on the Internet]. Rome. 2003. [cited 2003 Set 15]. Available from: URL: http://www.fao.org/english/ newsroom/news/ 2003/20846_en.html

78. Programa fome zero [Internet]. Brasil. 2003 [acesso 2003 set 13]. Disponível em: URL: http://www.brasil. gov.br/planos.htm

79. João Paulo II. Mensagem do papa João Paulo II ao diretor-geral da FAO por ocasião do dia mundial da alimentação [Internet]. Roma. 2004 [acesso 2005 mar 8]. Disponível em: URL: http://www. vatican.va/ holy_father/john_paul_ii/messages/ food/documents/hf_jp-ii_mes_20041015_xxivworld -food-day_po.html

80. Food and Agriculture Organization. Biodiversity for food security [homepage on the Internet]. Rome. 2004 [cited 2005 Mar 8]. Available from: URL: http://www.fao.org/wfd/index_en.asp 
418 | A.I.M. COELHO et al.

81. América Latina: no início do século, poderemos ser 62 milhões de subnutridos. Nutrinews. 1990; 4(61):10.

82. Um bilhão de subalimentados. Nutrinews. 1990; 4(56):2.

83. Fome e desnutrição matam uma criança brasileira a cada 20 minutos. Nutrinews. 1989; 4(52):5.

84. Feliciello D, Garcia RWD. Cidadania e solidariedade: as ações contra a fome e a miséria. Rev Nutr. 1995; 8(1):83-100.
85. Castro Filho JF, editor. Josué de Castro. Rio de Janeiro: Fundação Brasileira para Conservação da Natureza. [Internet]. Brasil. 2003 [acesso 2003 set 13]. Disponível em: http://www.josuedecastro. com.br/port/frame. html

86. Menezes F, Burlandy L, Maluf RS. Princípios e diretrizes de uma política de segurança alimentar e nutricional. Brasília: Consea; 2004. 80p.

Recebido para publicação em 11 de novembro de 2002 e aceito em 16 de março de 2004. 